\title{
People's willingness to pay for health insurance in rural Vietnam Curt Lofgren ${ }^{*}$, Nguyen X Thanh ${ }^{2}$, Nguyen TK Chuc ${ }^{3}$, Anders Emmelin ${ }^{1}$ and Lars Lindholm ${ }^{1}$
}

Address: ${ }^{1}$ Umeå International School of Public Health, Umeå University, Sweden, ${ }^{2}$ Institute of Health Economics, Edmonton, Canada and ${ }^{3}$ Dept. of Health Economics, Faculty of Public Health, Hanoi Medical University, Vietnam

Email: Curt Lofgren* - curt.lofgren@epiph.umu.se; Nguyen X Thanh - tnguyen@ihe.ca; Nguyen TK Chuc - ntkchuc020254@gmail.com; Anders Emmelin - anders.emmelin@epiph.umu.se; Lars Lindholm - lars.lindholm@epiph.umu.se

* Corresponding author

Published: II August 2008

Cost Effectiveness and Resource Allocation 2008, 6:16 doi:10.1 186/1478-7547-6-16

This article is available from: http://www.resource-allocation.com/content/6/1/16

(C) 2008 Lofgren et al; licensee BioMed Central Ltd.

This is an Open Access article distributed under the terms of the Creative Commons Attribution License (http://creativecommons.org/licenses/by/2.0), which permits unrestricted use, distribution, and reproduction in any medium, provided the original work is properly cited.

Received: 7 February 2008

Accepted: II August 2008

\begin{abstract}
Background: The inequity caused by health financing in Vietnam, which mainly relies on out-ofpocket payments, has put pre-payment reform high on the political agenda. This paper reports on a study of the willingness to pay for health insurance among a rural population in northern Vietnam, exploring whether the Vietnamese are willing to pay enough to sufficiently finance a health insurance system.
\end{abstract}

Methods: Using the Epidemiological Field Laboratory for Health Systems Research in the Bavi district (FilaBavi), 2070 households were randomly selected for the study. Existing FilaBavi interviewers were trained especially for this study. The interview questionnaire was developed through a pilot study followed by focus group discussions among interviewers. Determinants of households' willingness to pay were studied through interval regression by which problems such as zero answers, skewness, outliers and the heaping effect may be solved.

Results: Households' average willingness to pay (WTP) is higher than their costs for public health care and self-treatment. For $70-80 \%$ of the respondents, average WTP is also sufficient to pay the lower range of premiums in existing health insurance programmes. However, the average WTP would only be sufficient to finance about half of total household public, as well as private, health care costs. Variables that reflect income, health care need, age and educational level were significant determinants of households' willingness to pay. Contrary to expectations, age was negatively related to willingness to pay.

Conclusion: Since WTP is sufficient to cover household costs for public health care, it depends to what extent households would substitute private for public care and increase utilization as to whether WTP would also be sufficient enough to finance health insurance. This study highlights potential for public information schemes that may change the negative attitude towards health insurance, which this study has uncovered. A key task for policy makers is to win the trust of the population in relation to a health insurance system, particularly among the old and those with relatively low education. 


\section{Background}

Health financing in Vietnam relies mainly on out-ofpocket payments, which in 2000 were estimated to constitute as much as $80 \%$ of total health care expenditure [1]. More recent estimates are somewhat lower - around twothirds [2]. The share of households facing catastrophic health care expenditure may be as high as $10 \%$ [3]. In this context, the need for furthering prepayment reform in Vietnam has been highlighted by many, and it is the goal of the Vietnamese government to achieve health insurance coverage for all citizens by 2010 [4].

Today there are two forms of health insurance for the Vietnamese: firstly compulsory health insurance for those that have formal employment, which was introduced in 1993 and now covers $9 \%$ of the population; secondly, there is voluntary health insurance, which was introduced in 1994 and now covers $11 \%$ of the population. In addition there are two programs: Health Care Funds for the Poor, which in 2003 replaced the Free Health Care Cards for the Poor, and free health care for children $0-5$ years of age, which was established in 1991. Today these programs cover $18 \%$ and $11 \%$ of the population, respectively $[2,5]$.

This means that around half of the population today is covered by health insurance or the two special programs. The task now is to attain coverage for the remaining half, which will, most likely, be a more difficult task $[2,6]$.

This paper reports on a study of willingness to pay (WTP) for health insurance in Bavi, a rural district in northern Vietnam. Most of the inhabitants of Bavi are farmers who are not covered by health insurance. To our knowledge there is no other study of willingness to pay for health insurance in Vietnam, and few other studies of WTP for health care in the country; we found only one estimating WTP for obstetric delivery preferences [7]. There are, however, a number of other studies on health insurance in Vietnam, particularly on the effects on health care utilization and household out-of-pocket health expenditure. Several studies from recent years have found that voluntary health insurance is likely to increase considerably the visits to health care facilities and reduce out-of-pocket spending [8-10], whilst also leading to less self-treatment (buying of drugs without medical advice from professionals) $[11,12]$. Compulsory insurance has been found to increase health care utilization more than voluntary health insurance [13], and the Health Care Fund for the Poor also appears to increase the use of health services, particularly inpatient care [5]. These findings are of interest for our study, especially concerning the question of whether the WTP we have estimated is sufficient to finance viable health insurance. This is discussed below in relation to our results.
WTP for health insurance has been studied in other developing countries, although the number of studies is relatively small. In a study from a city in China, the WTP of informal sector workers to join an existing health insurance package for formal workers has been studied [14]. The average WTP was found to be higher than the cost of expanding such an insurance system. In Burkino Faso, the feasibility of a community-based health insurance package was studied in a rural area. Based on the WTP estimates, it was found to be feasible if health service utilization did not increase by more than $28 \%[15,16]$. In Ghana a WTP study of informal sector workers showed that $64 \%$ would sign up for health insurance for a reasonable (compared to costs) premium [17]. In Iran it was found, based on the respondents' WTP, that the existing health insurance system in urban areas could be introduced in rural areas [18], and finally, a WTP study in a rural area in India was used as a basis for discussing the content of health policy reform [19]. In the absence of WTP studies of health insurance in Vietnam, the above studies from other countries are of interest as reference points for our findings on the determinants of WTP. These comparisons are made in the discussion section.

We first present the methods used, including the rationale for using the WTP technique, the study design, the surveillance system used to collect the data, hypotheses about determinants for WTP and the method used to elicit WTP. This is followed by discussion of the econometric method used; due to the typical heaping of WTP answers we have used interval regression. Results are then presented and finally a methodological discussion, including potential bias, and a discussion of the results and their policy implications.

\section{Methods}

It is becoming increasingly popular in health economics to use the WTP approach to elicit the value people place on health and health care activities [20]. In the absence of monetary measurements of such values found on functioning markets - where consumers reveal how much of other goods they are willing to sacrifice to get a certain product - researchers instead ask potential consumers how much they would be willing to pay [21]. An advantage of this technique is that it measures the strength of consumer demand in monetary units, which can then be compared to costs [22]. Respondents are presented with a hypothetical scenario and then asked about their maximum willingness to pay for, for example, joining a health insurance scheme. Below we present the basis for data collection, followed by the design of our WTP study.

In 1999, in collaboration with Vietnamese and Swedish public health scientists, the Epidemiological Field Laboratory for Health Systems Research (FilaBavi) was estab- 
lished in the Bavi district of Vietnam, whose centre lies some $60 \mathrm{~km}$ west of Hanoi [23]. In 1999 a baseline household survey was undertaken followed by quarterly surveillance of vital events and complete re-surveys every two years.

The Bavi district has a population of 235,000 . For the surveillance database a random selection of 67 out of 352 clusters was made, with probability proportional to size. This means that we do not have to adjust for clustering effects in the estimations.

The surveillance database includes a population of 51,024 in 11,089 households. Each cluster was based on a village and consisted of 41 to 512 (mean 146) households with a population of 185 to 1,944 (mean 676). The largest clusters were then divided into 3, thereby in total there are 69 clusters in FilaBavi.

In 2004, 30 households were randomly selected for the present study from each cluster in the FilaBavi surveillance database, which gives a total of 2,070 households. Of these, complete interviews were held within 2,063 households. The aim of this study was to interview the heads of households only, most of which are men. In the FilaBavi database this share is $62 \%$. To ensure that there would be a reasonable proportion of female respondents, households were deliberately selected for this study so that half of the household heads would be women.

To interview only heads of households, however, turned out to be too time consuming. Therefore, interviewers restricted themselves to interviewing the head of the household if this person was at home at the time of the interview, or the spouse if the head could not be contacted; in total, $51 \%$ of the respondents were heads of households (table 1). An indicator variable has been included in the regression models to control for possible bias in relation to this. Of the interviewed household heads $44 \%$ were female, but of the total number of interviewees $64 \%$ were female. There is an indicator variable in the estimations controlling for gender. However, it should be recognized that there is a validity problem concerning the selection of households since female-headed households may be more disadvantaged than others. This is analyzed in the discussion section.

This is a study of household WTP, rather than individual WTP, as the economic decision to purchase health care among these rural and mostly farmer households is more likely to be a household decision and not an individual one. This is a common approach when studying rural communities in developing countries. Of the six previously cited studies of WTP for health insurance in developing countries (other than Vietnam), four of them estimate household WTP.

The interviewers in this study conduct regular surveys for the FilaBavi database. They are all educated to at least high school level and have received special training for their task. For testing the questionnaire, in particular the scenarios, a pilot of 15 in-depth interviews with heads of households outside the study sample was performed by the researchers. The version of the questionnaire developed on that basis was then discussed in four focus groups consisting of interviewers. The purpose of the focus groups was for training of the interviewers and further refining of the questionnaire. Before going to the field, the interviewers were trained twice, using a role-play technique on how to use the questionnaires. They were strictly supervised throughout the study period.

The choice set described and explained to respondents is presented in Figure 1. It consists of three different health

Table I: Respondent and household characteristics

\begin{tabular}{ll}
\hline Variable name & Description \\
\hline Male & Male $=$ I, female $=0$ \\
Age & Age in years \\
Farmer & Farmer $=$ I, all other occupations $=0$ \\
Morethanprimary & More than primary education $=1$, otherwise 0 \\
Membershh & Number of members in the household \\
Children & Number of children, 0 to 5 years age, in the household \\
Elderly & Number of persons, 65 years and older, in the household \\
Chronic & One or more persons in the household has a chronic disease $=1,0$ otherwise \\
Hcneed & At least one person in the household needed health care during the last year $=1,0$ otherwise \\
Insureexp & The household has insurance (of any kind) = I, 0 otherwise \\
Poor & The household is classified as poor by local leaders = I, 0 otherwise \\
Rich & The household is classified as rich by local leaders = I, 0 otherwise \\
Head & The respondent is the household head = I, 0 otherwise
\end{tabular}

*The mean value for indicator variables shows the proportion for the category which assumes the value I. For e.g. the variable Farmer, the mean value shows that $74 \%$ of the respondents are farmers. 
A. Households pay the full cost for each visit to the Communal Health Station or District Health Centre and for medicine prescribed by the doctor. Households that are not able to pay will not receive any services. A service is given at cost price - there is no profit. There are no exemption cards. The total annual cost for a household will depend on how many members will be ill and will visit the Communal Health Station or District Health Centre during the year.

B. All households in the district are compulsory (obliged) to pay an annual premium to a local health care fund when crops are sold. There are no exemption cards. The fee is based on how much income the households have. The higher income, the higher the fee. Thereby all members in the household are entitled to free health care at the Communal Health Station or District Health Centre and free medicine if prescribed by the doctor. If care at higher levels is needed, the insured patient will be supported by an amount based on the cost per bed day at the District Health Centre level. The fund will be managed by the Commune People Committee (or voted representative).

C. Each household can choose to voluntarily pay an annual premium to a local health care fund when crops are sold. The fee is based on the number of people in the household and the fee is higher for children under five and elderly over 65 because they are expected to use more health care. All persons in the household paying the fee are entitled to free health care at the Communal Health Station or District Health Centre and free medicine if prescribed by the doctor. If care at higher levels is needed, the insured patient will be supported by an amount based on the cost per bed day at the District Health Centre level. The fund will be managed by the Commune People Committee (or voted representative).

\section{Figure I}

Hypothetical scenarios.

care financing systems: A was an out-of-pocket model similar to the present system in Bavi, whilst B and C had identical benefit packages but were based on different financing schemes. B was a compulsory health insurance scheme based on community rating, and $\mathrm{C}$ was a voluntary scheme based on risk rating.

The three alternatives cover different financing systems for public health care, which is obvious from the scenarios but was also clearly pointed out to respondents. The respondents were asked to choose which one of these health financing systems they would prefer to have in Bavi. All respondents (not only those that preferred B or C respectively) were then also asked about their WTP for system $B$, given that this system would be implemented in Bavi, and similarly for system C, given that system C would be implemented. The WTP question was of a Yes/ No nature in relation to a certain bid (insurance cost), with a follow-up question about maximum WTP.

The bid was calculated based on another study from FilaBavi [24] where the average health care costs for households within the district was estimated (table 2); in 2002 this was 520,000 VND per year, which corresponds approximately to 45,000 VND per month. This later figure was used as the bid given to respondents, who were asked: Given that system B/C is chosen, would you be willing to pay 45,000 VND per month for your household?
Respondents were then given an open question about their maximum WTP in each system. The WTP elicited using the above method is presented in the results section.

In the scenarios nothing was said about the respondents' expected health-seeking behavior. According to table 2, it

Table 2: Average household expenditure for health care in Bavi, July 200 I to June 2002, Vietnamese dong

\begin{tabular}{lrrr}
\hline & $\begin{array}{r}\text { for the } \\
\text { whole } \\
\text { year }\end{array}$ & $\begin{array}{r}\% \\
\text { average } \\
\text { per } \\
\text { month }\end{array}$ \\
\hline Public health care & 129267 & $25 \%$ & 10772 \\
Commune health stations & 23698 & $5 \%$ & 1975 \\
District health centres & 45621 & $9 \%$ & 3802 \\
Provincial hospitals & 32508 & $6 \%$ & 2709 \\
Central hospitals & 26895 & $5 \%$ & 2241 \\
Others & 545 & $0 \%$ & 45 \\
Private health care & 283342 & $55 \%$ & 23612 \\
Self-treatment & 60338 & $12 \%$ & 5028 \\
Total curative exp & 472947 & $91 \%$ & 39412 \\
Health insurance & 16227 & $3 \%$ & 1352 \\
Prevention \& rehabilitation & 29317 & $6 \%$ & 2443 \\
\hline Total & 518491 & $100 \%$ & 43208 \\
\hline
\end{tabular}

Source: Thuan NTB: The burden of household health care expenditure in a rural district in Vietnam. MPH thesis. Nordic School of Public Health, Sweden; 2002 
is clear that public health care stands for less than half of total health care expenditure in Bavi. A very large share for private health care was also found in a nationwide study using the Vietnam Living Standard Survey 97/98 [25]. In the background section above studies on the effects of health insurance in Vietnam were cited. It appears that one can expect that a growing number of persons signing up for health insurance will lead to increased utilization of public health services and less self-medication - a shift away from private to public services.

However, when presenting respondents with a WTP scenario it is very important that it can be clearly understood. We concluded that complicating the scenario by adding information about an expected change in health-seeking behavior would make it too complex. But this of course leads to uncertainty when interpreting the elicited WTP, a question addressed in the discussion section below.

In relation to this we based the bid to the respondents on the total (public as well as private) household health care expenditure. This includes not only curative expenditure but also expenditure for health insurance (3\%) and for prevention and rehabilitation (6\%) (table 2). The curative expenditure includes costs for consultations, drugs and tests and for traveling (6\%) and lodging (2\%) (unpublished data from [24]). We wanted households to consider WTP based on total health care costs although we did not specify or point to a possible substitution of providers.

Our choice of background variables (see table 1), which were also collected through the interviews, follow our hypotheses about the determinants for WTP. Health insurance demand is a function of, apart from the price of the insurance, the respondent's degree of risk aversion, perceived risk of injury/illness, perceived extent of the loss caused by illness/injury, and income [26].

Using insurance theory, assuming a decreasing marginal utility of income, it follows that the higher the degree of risk aversion, the higher WTP will be when all else is equal. This is also the case for the perceived extent of the loss incurred by illness or injury. For the perceived risk of illness or injury, however, the relationship is not this simple; for a small - and a large - risk, WTP may be relatively small. If the risk is 1 , illness will occur with certainty, and the individual is better-off not buying insurance (including a load factor) with a risk-rated premium. If the insurance is based on community rating, this individual may still benefit from insurance, however. We assume that the risks perceived by the households in this study are not in the relatively large risk segment, so that it is reasonable to hypothesize that an increase in perceived risk, all else being equal, leads to an increase in WTP. We also hypothesize that the higher the income, the higher the WTP.

Figure 2 illustrates the hypothesized effects of the study variables on the main determinants of WTP.

We hypothesize that five variables will affect risk aversion, the perceived extent of the loss and the perceived risk amongst respondents, namely; age, occupation, educational level, and the number of children and elderly in the household. The older the respondent is, the higher the perceived risk will be for him/her. We assume that the degree of risk aversion increases with age, as does the perceived extent of the loss. An older person has more experience and can therefore more accurately envisage the affect of illness or injury on their household.

Farmers may be more vulnerable than other occupational groups, as illness/injury during critical periods of the year, such as at harvest, may have a proportionally greater affect on income than the duration of illness/injury. We can assume that respondents who have been educated to a relatively high level will have more knowledge about the effects of and need for health care due to illness. Finally, risk is also higher for children and the elderly, therefore risk aversion, perceived loss and risk may be higher the more children and elderly there are in a household.

The total number of household members and the number amongst them with chronic diseases are assumed to increase the perceived extent of the loss, as well as the perceived risk. Utilization of health care during the last year may also be an indicator of greater awareness of what might happen in case of illness/injury.

We employ the common assumption that women have a higher degree of risk aversion than men and that they have a higher risk of illness. Finally, households that have some sort of insurance (not only health insurance) have shown that they have a greater risk aversion than those with no insurance.

We have discussed above individual (or household) determinants of WTP. An interesting discussion today concerns the importance of "social determinants" in the form of social capital that could significantly affect household preferences for health insurance [27]. There is no clear consensus surrounding the definition of social capital [28], but it is generally agreed that it concerns informal networks that are established between households, and furthermore the trust and solidarity that characterizes these networks [27].

Interestingly, the existence of social capital may affect WTP for health insurance both positively and negatively. 


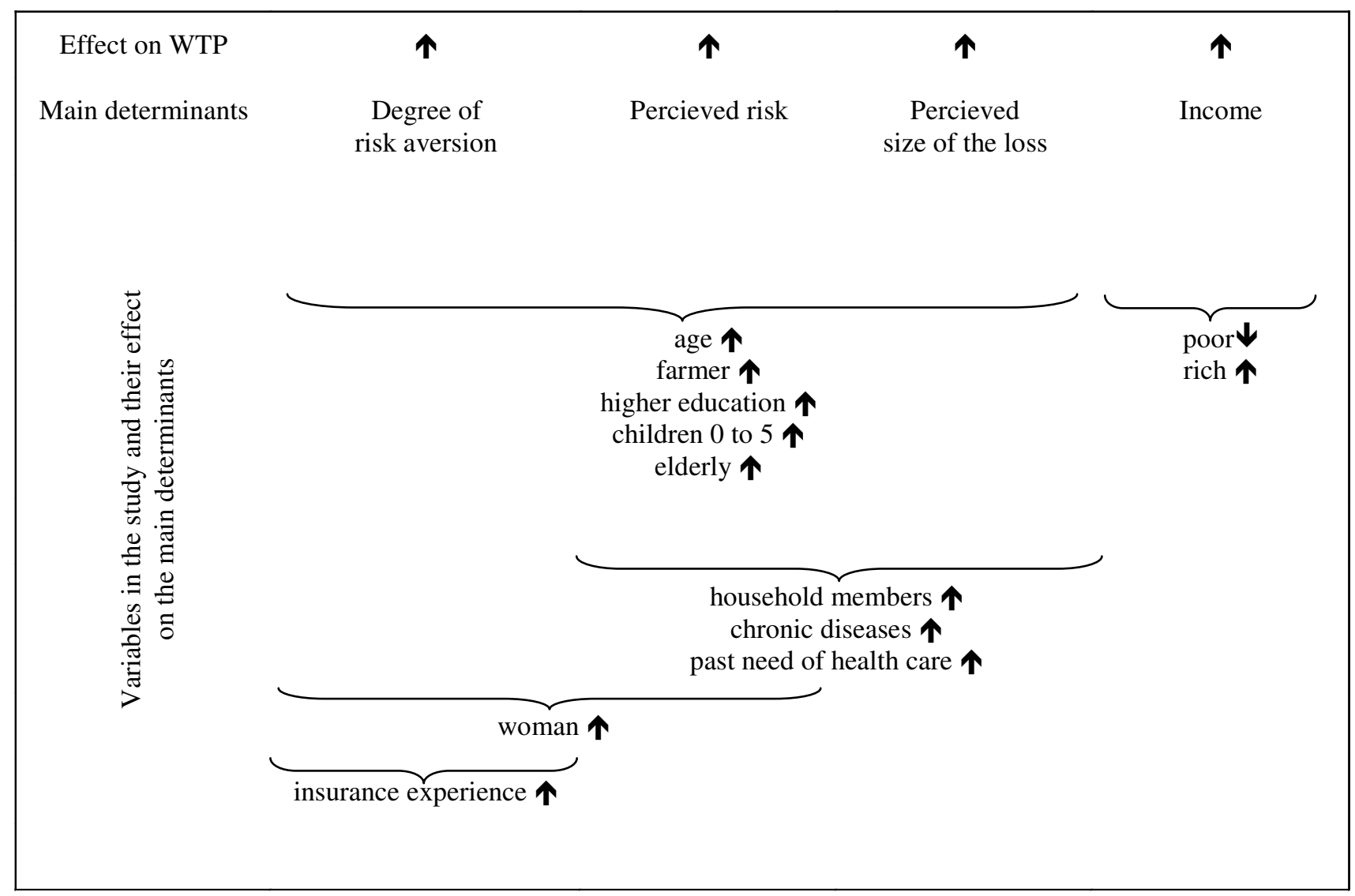

Figure 2

The main determinants of WTP and the variables.

To the degree that households trust one another in a community, they may also trust community-based health insurance schemes similar to those presented in the scenarios, which would, all else being equal, increase WTP. However, the existence of informal risk-sharing networks may also tend to "crowd out" formal health insurance, which would lead to lower WTP $[27,28]$. Unfortunately we have no information about and no variables that measure social capital, the implications of which are explored in the discussion section below.

There are four problems common to many WTP studies: i) the distribution of stated WTP is skewed; ii) some respondents will state a zero WTP; iii) other respondents will state a WTP very different from most of the respondents (outliers); and iv) respondents' WTP will tend to concentrate - "heap" - around certain values.

Skewness is often dealt with by using a log-normal model. The zero cases will then have to be excluded and outliers are also often excluded based on different criterions. The heaping effect, however, is often ignored. The fact that respondents appear to concentrate on convenient values suggests that their stated WTP represents a certain interval, rather than a precise amount. Torelli and Trivelato [29] have shown that this behaviour, if not considered, may disguise true relationships.

The heaping effect in our data is illustrated in table 3. About one-fifth of the respondents state a zero WTP in system B and almost one-third do so in system C. It is obvious from table 3 that the other respondents concentrate on values such as 5,000,10,000, 15,000 VND and so on. It is also noteworthy in table 3 that one respondent stated a WTP of 22 VND, which is an amount that hardly differs from zero in this context. This is addressed further in the methodological part of the discussion section.

If we assume that respondents' stated WTP represents intervals rather than precise measurements then this must be considered in the econometric method. We have done so by using interval or grouped data regression [30]. We estimate the following model: 
Table 3: Household WTP in the two insurance systems

\begin{tabular}{|c|c|c|c|c|c|}
\hline \multicolumn{3}{|c|}{ Compulsory insurance (B) } & \multicolumn{3}{|c|}{ Voluntary insurance (C) } \\
\hline Stated WTP & $\begin{array}{r}\text { No of } \\
\text { households }\end{array}$ & Percent & Stated WTP & $\begin{array}{r}\text { No of } \\
\text { households }\end{array}$ & Percent \\
\hline 0 & 438 & $21 \%$ & 0 & 617 & $30 \%$ \\
\hline 22 & I & $0 \%$ & 2000 & 5 & $0 \%$ \\
\hline 2000 & 4 & $0 \%$ & 3000 & 6 & $0 \%$ \\
\hline 3000 & 10 & $0 \%$ & 4000 & I & $0 \%$ \\
\hline 4000 & 1 & $0 \%$ & 4500 & I & $0 \%$ \\
\hline 4500 & I & $0 \%$ & 5000 & 115 & $6 \%$ \\
\hline 5000 & 120 & $6 \%$ & 7000 & I & $0 \%$ \\
\hline 7000 & 3 & $0 \%$ & 7500 & I & $0 \%$ \\
\hline 8000 & 2 & $0 \%$ & 8000 & 2 & $0 \%$ \\
\hline 10000 & 378 & $18 \%$ & 10000 & 334 & $16 \%$ \\
\hline 15000 & 158 & $8 \%$ & 12000 & I & $0 \%$ \\
\hline 18000 & I & $0 \%$ & 15000 & $|4|$ & $7 \%$ \\
\hline 20000 & 453 & $22 \%$ & 20000 & 395 & $19 \%$ \\
\hline 22000 & 4 & $0 \%$ & 22000 & 3 & $0 \%$ \\
\hline 22500 & 4 & $0 \%$ & 22500 & 7 & $0 \%$ \\
\hline 25000 & 40 & $2 \%$ & 25000 & 41 & $2 \%$ \\
\hline 27500 & I & $0 \%$ & 27500 & 2 & $0 \%$ \\
\hline 30000 & 112 & $5 \%$ & 30000 & 105 & $5 \%$ \\
\hline 35000 & 5 & $0 \%$ & 35000 & 2 & $0 \%$ \\
\hline 40000 & 7 & $0 \%$ & 40000 & 7 & $0 \%$ \\
\hline 45000 & 261 & $13 \%$ & 45000 & 223 & $11 \%$ \\
\hline 50000 & 36 & $2 \%$ & 50000 & 35 & $2 \%$ \\
\hline 60000 & 4 & $0 \%$ & 55000 & I & $0 \%$ \\
\hline 70000 & 3 & $0 \%$ & 60000 & 5 & $0 \%$ \\
\hline 80000 & 1 & $0 \%$ & 70000 & 3 & $0 \%$ \\
\hline 90000 & 1 & $0 \%$ & 80000 & I & $0 \%$ \\
\hline 100000 & 10 & $0 \%$ & 90000 & I & $0 \%$ \\
\hline 150000 & 1 & $0 \%$ & 100000 & 6 & $0 \%$ \\
\hline 200000 & 2 & $0 \%$ & 225000 & I & $0 \%$ \\
\hline 225000 & 1 & $0 \%$ & & & \\
\hline Total & 2063 & $100 \%$ & Total & 2063 & $100 \%$ \\
\hline
\end{tabular}

Suppose $y_{i}^{*}$ represents respondents' true WTP, which is a $\quad y_{i}=7$ when $27500<\gamma_{i}^{*} \leq 32500 \mathrm{VND}$ variable we cannot observe. What we do observe is another variable $y_{i}$ for which

$y_{i}=8$ when $32500<\gamma_{i}^{*} \leq 37500 \mathrm{VND}$

$y_{i}=1$ when $y_{i}^{*} \leq 2500 \mathrm{VND}$

$y_{i}=9$ when $37500<y_{i}^{*} \leq 42500 \mathrm{VND}$

$y_{i}=2$ when $2500<y_{i}^{*} \leq 7500 \mathrm{VND}$

$y_{i}=10$ when $42500<\gamma_{i}^{*} \leq 47500 \mathrm{VND}$

$y_{i}=3$ when $7500<y_{i}^{*} \leq 12500 \mathrm{VND}$

$y_{i}=11$ when $47500<\gamma_{i}^{*} \leq 52500 \mathrm{VND}$

$y_{i}=4$ when $12500<y_{i}^{*} \leq 17500 \mathrm{VND}$

$y_{i}=13$ when $52500<y_{i}^{*}$

$y_{i}=5$ when $17500<y_{i}^{*} \leq 22500 \mathrm{VND}$

Suppose that

$y_{i}=6$ when $22500<\gamma_{i}^{*} \leq 27500 \mathrm{VND}$

$\ln \gamma_{i}^{*}=\beta x_{i}+\varepsilon_{i}$ where $\varepsilon_{i} \sim \mathrm{N}\left(0, \sigma^{2}\right)$ 
In this case the likelihood function is

$$
\begin{aligned}
& L=\prod_{y_{i}=1} \Phi\left(\frac{\ln 2500-\beta x_{i}}{\sigma}\right) * \\
& * \prod_{y_{i}=2}\left[\Phi\left(\frac{\ln 7500-\beta x_{i}}{\sigma}\right)-\Phi\left(\frac{\ln 2500-\beta x_{i}}{\sigma}\right)\right] * \\
& * \prod_{\gamma_{i}=3}\left[\Phi\left(\frac{\ln 12500-\beta x_{i}}{\sigma}\right)-\Phi\left(\frac{\ln 7500-\beta x_{i}}{\sigma}\right)\right] * \bullet \bullet \\
& \bullet \bullet \bullet * \prod_{\gamma_{i}=11}\left[\Phi\left(\frac{\ln 52500-\beta x_{i}}{\sigma}\right)-\Phi\left(\frac{\ln 47500-\beta x_{i}}{\sigma}\right)\right] * \\
& * \prod_{\gamma_{i}=12}\left[1-\Phi\left(\frac{\ln 52500-\beta x_{i}}{\sigma}\right)\right]
\end{aligned}
$$

Using interval or grouped data regression solves the problems mentioned above and the heaping effect is considered. Also, the logarithm of the dependent variable can be used adjusting for skewness. Still, zero answers for WTP can be included. (If someone imagines the existence of negative WTP reflected in zero answers this is also included.) Outliers are kept in the highest interval.

The likelihood function has been maximized using STATA 8.0.

The Research Ethics Committee at Umeå University has given ethical approval for the FilaBavi household surveillance system, including data collection on vital statistics (reference number 02-420), and specific approval for the stated preferences survey $(\$ 86 / 04)$. The study has also received ethical approval from Hanoi Medical University and the Ministry of Health in Hanoi. The interviewers obtained informed consent for the interviews from heads of households.

\section{Results}

In the choice between the three different financing systems presented in Figure 1, a majority (52\%) of respondents preferred out-of-pocket financing, system A. Among the rest, preferences were stronger for compulsory $(28 \%)$ rather than voluntary $(20 \%)$ health insurance. The results of the choice experiment are reported in Thanh et al. [31], where the determinants for the choice between the three systems are also studied.

The focus of the present paper is on the extent and determinants of WTP for health insurance. The respondents were asked two different types of questions; the first - analyzed in Thanh et al. [31] - concerned the choice of financing system and aimed to explore which of the three systems the respondents prefer over the others; in the second type of question - analyzed in this paper - respond- ents were asked how much they would be willing to pay given that a certain system (B or C) was chosen for Bavi. All of the respondents were asked these WTP questions, and not only those who preferred insurance over out-ofpocket. Below we first report the extent of WTP given the respective systems, and then present the estimations of what determines WTP.

The average household in Bavi spends about 520000 VND per year or around 45000 dong per month for health care of all sorts - private as well as public with both curative and preventive care. This finding is from a study within the FilaBavi project and was used as the starting bid in this study (table 2).

The average household WTP is lower than this, however (table 4). For the compulsory insurance the average household WTP is around 18000 dong per month. For the voluntary insurance it is even lower. If only those respondents who have a positive WTP are included, or only those households that prefer one of the health insurance alternatives over out-of-pocket financing, the average is 22 000-24 000 VND in the respective schemes. This elicited WTP corresponds to half of the total health care expenditure of the average household in Bavi.

Total household health expenditure covers public health care (11 $000 \mathrm{VND})$, self-treatment (5 $000 \mathrm{VND})$ and private health care (24000 VND), which gives a total of 40 000 VND (table 2). Added to this is the cost of health insurance, prevention and rehabilitation, which gives a total of around $45000 \mathrm{VND}$, hence the starting bid for respondents. Thus, the average WTP for all respondents covers more than the costs for public health care and selftreatment but does not cover costs for private care. Whether one should conclude that this represents a favourable basis for the expansion of health insurance in this district depends, among several things, on the assumptions one makes about how respondents are likely to behave once insured - to what extent would they substitute self-treatment and private health care for public health care, and to what extent would they increase their demand for health care? This is discussed in the next section. As a basis for the discussion we will below compare to existing insurance premiums.

Health insurance systems operate in Vietnam where the premiums correspond to a lower level of household health care expenditure than reported above for Bavi. For the community-based health insurance schemes offered in rural areas by the Vietnam Social Security, premiums range from $60,000 \mathrm{VND}$ to $100,000 \mathrm{VND}$ per person and year. [32]. The lower boundary of this range corresponds to 22000 VND per household and month in Bavi, i.e. an amount equal to the WTP of households whose WTP is 
Table 4: Respondents' WTP for the two forms of health insurance

\begin{tabular}{|c|c|c|c|c|c|c|}
\hline & \multicolumn{2}{|c|}{$\begin{array}{l}\text { For household } \\
\text { per month }\end{array}$} & \multicolumn{2}{|c|}{$\begin{array}{l}\text { Per person } \\
\text { and year* }\end{array}$} & \multirow[b]{2}{*}{$\begin{array}{l}\% \text { of } \\
\text { respon- } \\
\text { dents }\end{array}$} & \multirow[b]{2}{*}{$\mathrm{N}$} \\
\hline & Mean & Median & Mean & Median & & \\
\hline \multicolumn{7}{|l|}{ Compulsory health insurance } \\
\hline WTP for all respondents & 17873 & 15000 & 47661 & 40000 & $100 \%$ & 2063 \\
\hline WTP for respondents whose WTP $>0$ & 22690 & 20000 & 60507 & 53333 & $79 \%$ & 1625 \\
\hline WTP for respondents who prefer $\mathrm{HI}$ over OOP & 23650 & 20000 & 63067 & 53333 & $48 \%$ & 999 \\
\hline \multicolumn{7}{|l|}{ Voluntary health insurance } \\
\hline WTP for all respondents & 15588 & 10000 & 41568 & 26667 & $100 \%$ & 2063 \\
\hline WTP for respondents whose WTP > 0 & 22239 & 20000 & 59304 & 53333 & $70 \%$ & I 446 \\
\hline WTP for respondents who prefer $\mathrm{HI}$ over OOP & 22501 & 20000 & 60003 & 53333 & $48 \%$ & 999 \\
\hline
\end{tabular}

*Average household size is 4.5 persons.

$\mathrm{HI}=$ health insurance.

OOP out-of-pocket payments

larger than zero. These groups of households make up $70 \%$ (for the voluntary insurance system) and $80 \%$ (for the compulsory insurance system) of the total group of households (table 4). The Vietnam Social Security also offers a school health insurance system for students [33], for which premiums range from 10,000 VND to 45,000 VND per student and year. The upper boundary of that range is close to the average WTP for all households in this study.

We have compared a low-cost health care system to the income that would be generated through the WTP stated by the respondents. This is done for those in the Bavi population who prefer health insurance (compulsory or voluntary) over out-of-pocket health care payments. The estimation is explained in more detail in appendix 1 . We assume that the uninsured population who prefer health insurance, enrol in a health insurance scheme. We also assume that their health care utilization matches the national average and that non-treatment and self-treatment episodes are replaced by outpatient care at Community Health Centres. Furthermore, we assume that private users turn to public health care with the same patterns as public users. Finally, we assume that the length of stay at the provincial and central levels is the same as at the district level (see the WTP scenarios in Figure 1).

The total health care costs incurred by the target population per year were estimated as being 5.9 billion VND. The stated WTP for the same population would yield an income of the same magnitude, ranging from 5.6 to 5.9 million VND (table 5) based on a WTP between 60,000 and 63,000 VND per person per year.
The estimations of what determines WTP are presented in tables 6 and 7. As hypothesized, the income variables are significant determinants for WTP in system B and close to significant (or significant at the 10\% level) in system C. Being a rich household is significant, or close to significant, and positive in some of the estimations. Belonging to the group of poor households is significant, or close to significant, and negative in some of the estimations.

The larger the household the bigger the WTP. This holds true for all estimations. In system C, WTP is also higher as the number of children in the household increases. WTP is also higher for households that have at least one member with a chronic disease, and is true for three of the estimations. All of the estimations show that WTP is higher if the respondent is educated beyond primary level.

All of the above results were expected and are in line with our hypotheses. We did not expect, however, that WTP would fall with increasing age of the respondent, and that having at least one person in the household who needed health care during the last year would decrease WTP in three of the estimations. Also, being a farmer is significant and negative in one of the estimations.

\section{Discussion}

Methodological considerations

There are a large number of potential biases in a WTP study. We follow the typology developed by Mitchell and Carson [34] when discussing the biases relevant to our study and whether they may pose a problem or not. Mitchell and Carson classify the ("potential response effect") biases into three large groups: 
Table 5: Total yearly income for a health insurance scheme and estimated health care costs

\begin{tabular}{|c|c|c|c|c|c|c|}
\hline $\begin{array}{l}\text { Health insurance } \\
\text { scheme }\end{array}$ & $\begin{array}{l}\text { WTP per } \\
\text { household } \\
\text { and month } \\
\text { (I) }\end{array}$ & $\begin{array}{l}\text { Household } \\
\text { members } \\
\text { (2) }\end{array}$ & $\begin{array}{l}\text { Premium per } \\
\text { person and } \\
\text { month } \\
\text { (3) }\end{array}$ & $\begin{array}{l}\text { Premium per } \\
\text { person and } \\
\text { year } \\
(4)\end{array}$ & $\begin{array}{c}\text { Enrolees } \\
\text { (5) }\end{array}$ & $\begin{array}{l}\text { Total yearly } \\
\text { income } \\
(6)\end{array}$ \\
\hline Compulsory (B) & 23,650 & 4.5 & 5,256 & 63,067 & 93,949 & $5,925,050,266$ \\
\hline \multirow[t]{3}{*}{ Voluntary (C) } & 22,501 & 4.5 & 5,000 & 60,003 & 93,949 & $5,637,190,530$ \\
\hline & $\begin{array}{l}\text { Health } \\
\text { care costs } \\
\text { per } \\
\text { household and } \\
\text { month } \\
\text { (12) }\end{array}$ & $\begin{array}{l}\text { Household } \\
\text { members } \\
\text { (II) }\end{array}$ & $\begin{array}{l}\text { Health care } \\
\text { costs per person } \\
\text { and month } \\
\text { (10) }\end{array}$ & $\begin{array}{l}\text { Health care } \\
\text { costs per } \\
\text { person and } \\
\text { year } \\
\text { (9) }\end{array}$ & $\begin{array}{l}\text { Enrolees } \\
\quad(8)\end{array}$ & $\begin{array}{l}\text { Total health } \\
\text { care costs } \\
\text { (VND) } \\
\text { (7) }\end{array}$ \\
\hline & 23,572 & 4.5 & 5,238 & 62,858 & 93,949 & $5,905,491,555$ \\
\hline
\end{tabular}

Note: The health insurance schemes include only those households that prefer health insurance to out-of-pocket payments. For the estimation of health care costs see appendix I.

$(3)=(1) /(2)$.

(4) $=(3) * 12$ months.

(6) $=(4) *(5)$.

$(9)=(7) /(8)[(7)$ is from table $\mathrm{AI}]$.

$(10)=(9) / 12$ months.

$(12)=(10) *(11)$

i) The first group concerns cases where respondents misrepresent their true WTP. For example, this could be a strategic bias when a respondent purposely states a WTP higher or lower than the true one because the respondent in his or hers self-interest wants to influence the result of the study. It could also be a compliance bias when a respondent gives an answer he or she believes the interviewer wants to hear.

ii) The second group concerns cases where the elicitation method implicitly gives a "correct" value for the WTP. The starting point bias is one of these biases. A bid is given to the respondent and thereby a cue to where the WTP might lay.

iii) The third group concerns different misspecifications of the scenario. In this case the respondent perceives the scenario differently to what is intended. Among these biases, the part-whole bias is of particular interest to our study It means that the respondent includes something which is not in the scenario or excludes something which is there.

In our study, instead of choosing a direct open-ended WTP question (simply asking the respondent what his/her maximum WTP is) we chose a take it or leave it question with an open ended follow-up; the reason being that respondents may find it hard to answer direct open-ended questions and that this in turn may lead to many protest zero answers. With our format, there is instead a risk for a starting point bias, however, the results do not indicate that this is a problem. Most respondents give a WTP far lower than the bid they were given. Only 15\% (for com- pulsory health insurance) and 13\% (voluntary health insurance) stated a WTP equal to or higher than the bid they were given (table 3 ). The average WTP was less than half of the bid.

Some respondents did give a WTP equal to zero, $21 \%$ for the compulsory insurance and $30 \%$ for the voluntary insurance. But it is not likely that these were protest zeros in the sense discussed above. The scenario was carefully explained by the interviewers and a concrete bid was given. The interview process was closely monitored and the interviewers did not report any problems in making the bid understandable for the respondents. However, there could be WTP zeros given, not representing true WTP, for another reason; there may be a strategic bias. Almost all of the respondents $(90 \%)$ stating a zero WTP belong to the group preferring the out-of-pocket financing alternative over the health insurance alternatives (tables 8 and 9).

It may well be that some of them voted once more for their preferred system when they stated their WTP, even though the question was about their WTP given that someone else (the government) had chosen to implement a health insurance system. This may also be the case for the respondent who stated a WTP of 22 VND for compulsory health insurance, since this amount is very low indeed (table 3 ). We cannot determine to what extent this is a problem in our study. It was pointed out in the data section above that it is reasonable to assume that respondents have a larger (true) WTP for the financing alternative that they prefer, or conversely a lower WTP for the alterna- 
Table 6: Interval regression. WTP determinants for compulsory health insurance (system B)

\begin{tabular}{|c|c|c|c|c|c|c|}
\hline & \multicolumn{3}{|c|}{ I } & \multicolumn{3}{|c|}{2} \\
\hline & Coef. & z & $P>|z|$ & Coef. & $\mathrm{z}$ & $P>|z|$ \\
\hline Head & .0621513 & 0.87 & 0.382 & .042933 & 0.66 & 0.507 \\
\hline Male & .0785897 & 1.12 & 0.261 & .029905 & 0.47 & 0.638 \\
\hline Age & -.0106958 & -3.83 & 0.000 & -.0102374 & -4.03 & 0.000 \\
\hline Farmer & -.0367228 & -0.51 & 0.613 & $-.1386 \mid 46$ & -2.09 & 0.036 \\
\hline Morethanprimar & .1528767 & 2.24 & 0.025 & .1391636 & 2.25 & 0.025 \\
\hline \multicolumn{7}{|l|}{ y } \\
\hline Membershh & .1107999 & 5.35 & 0.000 & .0826442 & 4.38 & 0.000 \\
\hline Children & .0003272 & 0.01 & 0.995 & -.0011396 & -0.03 & 0.979 \\
\hline Elderly & -.0356463 & -0.65 & 0.518 & -.0058438 & -0.12 & 0.907 \\
\hline Chronic & $.173469 \mid$ & 2.43 & 0.015 & .062738 & 0.97 & 0.335 \\
\hline Hcneed & -.1701406 & -1.67 & 0.095 & -.0932201 & -1.00 & 0.315 \\
\hline Insurexp & .0495472 & 0.61 & 0.540 & -.0144759 & -0.20 & 0.844 \\
\hline Poor & -.1165337 & -1.28 & 0.201 & -.184308 & -2.22 & 0.027 \\
\hline Rich & .1986089 & 2.45 & 0.014 & .1885194 & 2.56 & 0.010 \\
\hline Prefcohi & & & & 1.129829 & 18.86 & 0.000 \\
\hline Prefvohi & & & & .8976605 & 13.31 & 0.000 \\
\hline \multirow[t]{5}{*}{ Constant } & 9.227955 & 47.50 & 0.000 & 8.89968 & 50.17 & 0.000 \\
\hline & Log likelihood = -5003.246I & \multicolumn{5}{|c|}{ Log likelihood = -4809.0038 } \\
\hline & $\operatorname{LR} \operatorname{chi} 2(13)=111.20$ & \multicolumn{5}{|c|}{ LR chi $2(15)=499.68$} \\
\hline & Prob $>$ chi2 $=0.0000$ & \multicolumn{5}{|c|}{ Prob $>$ chi $2=0.0000$} \\
\hline & Total number of observations & \multicolumn{5}{|c|}{ Total number of observations $=2022$} \\
\hline Variable name & \multicolumn{6}{|l|}{ Description } \\
\hline$\overline{\text { Prefcohi }}$ & \multicolumn{6}{|c|}{$\begin{array}{l}\text { Prefcohi }=1 \text { if the respondent prefers compulsory health insurance (system } B \text { ) over the other alternatives. Prefcohi }=0 \\
\text { otherwise. }\end{array}$} \\
\hline Prefvohi & \multicolumn{6}{|c|}{$\begin{array}{l}\text { Prefvohi }=I \text { if the respondent prefers voluntary health insurance }(\text { system } C) \text { over the other alternatives. Prefvohi }=0 \\
\text { otherwise }\end{array}$} \\
\hline
\end{tabular}

For an explanation of the other variables, see table I.

tives that they do not prefer. But if there is a strategic bias, WTP in this study is underestimated since there is no indication of inflated WTP answers (WTP being far lower than actual health care expenditure).

A compliance bias seems less likely because of the relatively low WTP given in relation to the bid. If the respondents wanted to please the interviewers they may be expected to give a WTP closer to the bid.

Another problem is found in the third group of potential biases described above; did the respondents understand the scenarios? Again, the interview process was well planned (including interviewer training and focus group discussions) and carefully monitored. There is therefore no reason to suspect that the respondents didn't understand the scenarios, however, they may not have trusted them.

The respondents may have generalized the problems of the existing health insurance systems in Vietnam to the hypothetical ones [31]. In reality, when using insurance, patients can risk longer waiting times and lower quality of care. They also run the risk of still having to pay considerable amounts out-of-pocket, e.g. in the form of gifts to the staff [9]. With this in mind, the respondents may not have believed or trusted that the health insurance described in the scenarios would deliver the benefits promised. If so there is an information bias. The WTP that respondents indicated may relate to benefits that are smaller than the intended benefits in the scenarios, and therefore the WTP may be underestimated.

The conclusion from this discussion of potential biases is therefore that there is a possibility that WTP estimates are underestimated for two reasons, strategic behavior and part-whole bias. The starting point and the compliance bias seem less likely.

It is also possible that WTP is underestimated in relation to the true WTP of the Bavi population, since the selection of households was conducted so that $50 \%$ of them would be headed by females. There is evidence that femaleheaded households are more disadvantaged than others 
Table 7: Interval regression. WTP determinants for voluntary health insurance (system C)

\begin{tabular}{|c|c|c|c|c|c|c|}
\hline & \multicolumn{3}{|c|}{1} & \multicolumn{3}{|c|}{2} \\
\hline & Coef. & z & $P>|z|$ & Coef. & z & $P>|z|$ \\
\hline Head & .1240847 & $\mathrm{I} .47$ & 0.142 & .0740998 & 1.02 & 0.309 \\
\hline Male & .1294685 & 1.56 & 0.119 & .0749992 & 1.05 & 0.294 \\
\hline Age & -.0083357 & -2.52 & 0.012 & -.007418 & -2.60 & 0.009 \\
\hline Farmer & .0144706 & 0.17 & 0.867 & -.112466 & -1.51 & 0.131 \\
\hline Morethanprimar & .20443 & 2.52 & 0.012 & .1703909 & 2.44 & 0.015 \\
\hline \multicolumn{7}{|l|}{ y } \\
\hline Membershh & .0996013 & 4.05 & 0.000 & .0646929 & 3.05 & 0.002 \\
\hline Children & .1119569 & 1.97 & 0.048 & .0792814 & 1.62 & 0.104 \\
\hline Elderly & -.0344205 & -0.53 & 0.599 & -.0092381 & -0.16 & 0.870 \\
\hline Chronic & .3078385 & 3.65 & 0.000 & .1541756 & 2.12 & 0.034 \\
\hline Hcneed & -.4161749 & -3.47 & 0.001 & -.3366622 & -3.27 & 0.001 \\
\hline Insurexp & .0769168 & 0.80 & 0.423 & -.0151158 & -0.18 & 0.855 \\
\hline Poor & $-.04 \mid 9754$ & -0.39 & 0.697 & -.153246 & -1.65 & 0.100 \\
\hline Rich & .1770999 & 1.84 & 0.066 & .1259169 & 1.52 & 0.129 \\
\hline Prefcohi & & & & 1.321762 & 19.56 & 0.000 \\
\hline Prefvohi & & & & 1.648773 & 21.81 & 0.000 \\
\hline \multirow[t]{5}{*}{ Constant } & 8.885455 & 38.61 & 0.000 & 8.452932 & 42.49 & 0.000 \\
\hline & Log likelihood $=-4820.0345$ & \multicolumn{5}{|c|}{ Log likelihood = -4522.9879 } \\
\hline & $\operatorname{LR} \operatorname{chi} 2(13)=97.41$ & \multicolumn{5}{|c|}{$\operatorname{LR}$ chi2 $(15)=691.51$} \\
\hline & Prob $>$ chi2 $=0.0000$ & \multicolumn{5}{|c|}{ Prob $>$ chi2 $=0.0000$} \\
\hline & \multicolumn{2}{|c|}{ Total number of observations $=2022$} & \multicolumn{3}{|c|}{ Total number of observations $=2022$} & \\
\hline Variable name & \multicolumn{6}{|c|}{ Description } \\
\hline Prefcohi & \multicolumn{6}{|c|}{$\begin{array}{l}\text { Prefcohi }=1 \text { if the respondent prefers compulsory health insurance (system B) over the other alternatives. Prefcohi }=0 \\
\text { otherwise. }\end{array}$} \\
\hline Prefvohi & \multicolumn{6}{|c|}{$\begin{array}{l}\text { Prefvohi }=I \text { if the respondent prefers voluntary health insurance (system C) over the other alternatives. Prefvohi }=0 \\
\text { otherwise }\end{array}$} \\
\hline
\end{tabular}

For an explanation of the other variables, see table I.

$[35,36]$; that a larger percent of them live in poverty than other households. Since income is positively related to WTP, this could mean that households in this study have a lower WTP than those of the entire Bavi population.

Table 8: The number of respondents stating a zero WTP for the compulsory health insurance system

\begin{tabular}{lcccc}
\hline & \multicolumn{3}{c}{ Preference for financing systems } & Total \\
\hline & $\begin{array}{c}\text { Out-of- } \\
\text { pocket }\end{array}$ & $\begin{array}{c}\text { Compulsory } \\
\text { health } \\
\text { insurance }\end{array}$ & $\begin{array}{c}\text { Voluntary } \\
\text { health } \\
\text { insurance }\end{array}$ & \\
\hline WTP $=0$ & 394 & 5 & 39 & 438 \\
WTP $>0$ & $90 \%$ & $1 \%$ & $9 \%$ & $100 \%$ \\
& 671 & 582 & 372 & 1625 \\
& $41 \%$ & $36 \%$ & $23 \%$ & $100 \%$ \\
\hline Total & 1065 & 587 & 411 & 2063 \\
& $52 \%$ & $28 \%$ & $20 \%$ & $100 \%$ \\
\hline
\end{tabular}

\section{WTP for health insurance}

The determinants of WTP in this study are mostly in line with our expectations; having a greater income, higher education, larger household and at least one household member with chronic disease increases WTP. We have not

Table 9: The number of respondents stating a zero WTP for the voluntary health insurance system

\begin{tabular}{lcccc}
\hline & \multicolumn{3}{c}{ Preference for financing systems } & Total \\
\hline & $\begin{array}{c}\text { Out-of- } \\
\text { pocket }\end{array}$ & $\begin{array}{c}\text { Compulsory } \\
\text { health } \\
\text { insurance }\end{array}$ & $\begin{array}{c}\text { Voluntary } \\
\text { health } \\
\text { insurance }\end{array}$ & \\
\hline WTP $=0$ & 557 & 59 & 1 & 617 \\
& $90 \%$ & $10 \%$ & $0 \%$ & $100 \%$ \\
WTP $>0$ & 508 & 528 & 410 & 1446 \\
& $35 \%$ & $37 \%$ & $28 \%$ & $100 \%$ \\
\hline Total & 1065 & 587 & 411 & 2063 \\
& $52 \%$ & $28 \%$ & $20 \%$ & $100 \%$ \\
\hline
\end{tabular}

For an explanation of the other variables, see table $\mathrm{I}$. 
found any other WTP study of health insurance from Vietnam for comparison, but the results reported from WTP studies in other developing countries (cited in the background section) show similar results in these respects.

We did not expect WTP in the present study to fall with increasing age, and also if the household had been in need of health care during the last year. In the studies from other developing countries the results on age are mixed, some report increasing, and others decreasing WTP with age. When variables similar to our "hcneed" (if the household had been in need of health care during the last year) are included in studies from other countries, the result is opposite to ours, which is noteworthy and discussed below.

For WTP for health insurance our results can be summarized as follows:

- The average WTP (18 $000 \mathrm{VND})$ covers the average costs for public health care (11 $000 \mathrm{VND})$.

- The average WTP is also sufficient to include self-treatment (5 $000 \mathrm{VND})$.

- For $70-80 \%$ of the respondents the average WTP (22 000 ) is sufficient to pay the lower range of premiums in the existing health insurance programme.

- It is feasible to design a low-cost health care system that could be financed - at least for the population who prefer insurance over an out-of-pocket system -given the WTP stated by the respondents.

- The average WTP would only be sufficient to finance about half of all health care costs, public as well as private.

The respondents were asked about their WTP for two insurance systems for public health care. These insurance systems would give them free health care and free prescribed drugs at the commune and district levels, and reimbursement at higher levels corresponding to the cost at the district level. In this situation there are two extreme alternatives for how the respondents could behave if insured:

1. They could substitute all private care for public care. Their WTP would not be sufficient to finance this.

2. They could continue using public health care at the same frequency as before. Their WTP would be enough to finance this.

Existing evidence indicates that something in between these two alternatives would happen. The studies on health insurance in Vietnam referred to in the background section show there will most likely be a shift from private care and self-treatment to public care, and that health service utilisation will increase. If these changes are substantial, the limit for what average WTP in this study can finance is soon reached.

There is a logical question here: In the situation these households are experiencing, with high out-of-pocket medical expenses and risk for catastrophic health expenditure, why do they not state a higher WTP? In the section above the possibility that WTP is underestimated was discussed. This is due both to a possible strategic and a partwhole bias. Some of the respondents who preferred outof-pocket financing to insurance may have stated a zero WTP for insurance. Some respondents may also have interpreted things in the insurance scenarios that were not meant to be there.

One such factor may be the informal payments, in the form of money or gifts to the staff, which are common. There are reports of such payments being as much as 14 times higher than official fees [37] and that they are higher in northern provinces than in the south [9]. Other studies have also suggested that respondents to surveys factor in these unofficial payments when answering [5]. This would mean that "free health care" in the insurance scenarios would not be interpreted as free at all.

Another such factor is the risk that in reality, when using insurance, patients can risk longer waiting times and lower quality of care [31]. The scenarios, at least implicitly, assume the same quality in public health care for both insured and uninsured. These factors could explain a possible underestimation of WTP.

There are also reasons for why the true WTP might be relatively low, with quality of public health care being one. In comparison with private care, public care may, for example, be less accessible, have a smaller drug supply and meet patients with less respect [25]. Perhaps this could help to explain why our variable "hcneed" - if the household had been in need of health care during the last year - turned out to be a negative determinant of WTP. People with recent experiences of health care are better judges of what private as well as public care can offer.

Furthermore, in the methods section the potential importance of social capital was discussed. One part of this is the trust for the community that people have or don't have. If the respondents in our survey did not trust the local community to deliver what is specified in the scenarios, measurements of social capital - which we don't have - could have provided better insight into this problem. Another part of social capital is informal risk-sharing. Studies have 
shown that this is common in Vietnam, for example in the form of people borrowing money from relatives and friends to pay for health care, and that this may decrease the interest in health insurance [38].

\section{Conclusion}

The goal for the Vietnamese government is to reach insurance or prepayment coverage for all citizens within a few years. Today, about half of the population is covered. Reaching the other half may prove to be harder than reaching the first. One way to study the possibilities for insurance expansion is to estimate the WTP for insurance - to find out how much other expenditure people are willing to sacrifice so that they can be insured or, put another way, what value they place on insurance.

This is, to our knowledge, the first such study in Vietnam. It has uncovered great scepticism of an insurance system; half of the respondents prefer an out-of-pocket system and the stated WTP is relatively low. It would, however, be wrong to conclude that it is too low. Under certain conditions, discussed above, people's WTP could sufficiently finance a health insurance system.

Our study leaves many questions for future research, some of which are: How much of the WTP result can be contributed to the product, public health care, and how much to competing informal risk-sharing networks? And how much can be contributed to the complexities of an insurance system in a setting where people are relatively inexperienced of such formal arrangements? It will take further quantitative and qualitative studies to uncover the answers to these questions.

Our findings on the determinants of WTP are, in this light, somewhat encouraging. WTP falls with increasing age and rises with more education. Older people may be less inclined to undergo change and therefore less ready to support a new, unknown system. People with higher education may be more confident in adjusting to, and trusting, a new system. These results are encouraging because they highlight a potential for public information schemes that could change the predominantly negative attitude towards health insurance that this study has uncovered. A key task for policy-makers is to win the trust of the population for a health insurance system, particularly among the old and those with relatively low education.

\section{Competing interests}

The authors declare that they have no competing interests.

\section{Authors' contributions}

CL performed the statistical analysis, drafted and revised the manuscript. NXT designed the questionnaire, was responsible for monitoring the interview process and was also responsible for drafting and revising the manuscript. NTKC, AE and LL participated in the conception, planning and design of the study and in the revisions of the manuscript. All co-authors read and approved the final manuscript.

\section{Appendix I. Estimation of minimum health care costs for the section of the population in Bavi who prefer health insurance (compulsory or voluntary) to out-of-pocket health care payments}

A little less than half of the respondents $(48.4 \%)$ stated that they prefer either compulsory or voluntary health insurance over out-of-pocket payments for health care. We have estimated a minimum health care cost for this part of the population by using data from the Vietnam National Health Survey 2002 [39]. These data apply to the whole country so the following estimations in table 10 and table 11 is a rough approximation.

\section{Assumptions}

Health care utilization patterns, health insurance coverage, number of sickness episodes per person and year and health care costs per episode in Bavi are similar to the national average.

Table AI: Estimated number of enrolees and sickness episodes

\begin{tabular}{lr}
\hline Population in Bavi: & 235,000 \\
\hline Percent of population insured: & $17.4 \%$ \\
Population un-insured: & $235,000 *(I-0.174)=194,110$ \\
Number expected to enrol in a health insurance scheme: & $194,110^{*} 48.4 \%=93,949$ \\
Number of sickness episodes per person per year*: & 3 \\
Number of sickness episodes among those enrolled in health insurance scheme: & $93,949 * 3=281,848$ \\
Of which: episodes in inpatient care: & $281,848 * 1.4 \% *=3946$ \\
episodes in outpatient care: & $281,848 * 28.1 \% *=79,199$ \\
episodes of self-treatment: & $281,848 * 65.9 \% *=185,738$ \\
episodes of non-treatment: & $281,848 * 4.6 \% *=12,965$
\end{tabular}

* Source: Vietnam National Health Survey 2002 
Table A2: Estimated health care costs for the expected enrolees in a health insurance scheme in Bavi

\begin{tabular}{|c|c|c|c|c|c|c|c|c|}
\hline & $\begin{array}{l}\text { Utiliza- } \\
\text { tion } \\
\text { rates } \\
(I)^{*}\end{array}$ & $\begin{array}{l}\text { Total } \\
\text { sickness } \\
\text { episodes } \\
(2)^{* *}\end{array}$ & $\begin{array}{l}\text { Sickness } \\
\text { episodes } \\
\text { (3) }\end{array}$ & $\begin{array}{l}\text { Weight to } \\
\text { distribute } \\
\text { the private } \\
\text { care } \\
\text { episodes } \\
\text { (4) }\end{array}$ & $\begin{array}{c}\text { Private care } \\
\text { episodes distributed } \\
\text { to public } \\
\text { facilities } \\
\text { (5) }\end{array}$ & $\begin{array}{l}\text { Expected sickness } \\
\text { episodes in } \\
\text { public } \\
\text { facilities } \\
(6)\end{array}$ & $\begin{array}{l}\text { Health care } \\
\text { cost per } \\
\text { episode } \\
(7)^{*}\end{array}$ & $\begin{array}{l}\text { Total costs } \\
1000 \text { VND } \\
\text { (8) }\end{array}$ \\
\hline Inpatients** & & 3,946 & & & & & & \\
\hline $\mathrm{CHC}$ & 0.158 & & 623 & 0.173246 & 60 & 684 & 104,000 & 71,097 \\
\hline $\mathrm{DHC}$ & 0.333 & & $|, 3| 4$ & 0.365132 & 127 & $|, 44|$ & 242,000 & 348,676 \\
\hline Provincial and central & 0.421 & & $I, 66 \mid$ & 0.461623 & 160 & 1,822 & 242,000 & 440,8 I 8 \\
\hline Private and others & 0.088 & & 347 & & & & & \\
\hline Outpatients $* *$ & & 79,199 & & & & & & \\
\hline $\mathrm{CHC}$ & 0.32 & & 25,344 & 0.659794 & 26,911 & 250,958 & 15,400 & $3,864,753$ \\
\hline $\mathrm{DHC}$ & 0.086 & & 6,811 & 0.177320 & 7,232 & 14,044 & 43,800 & 615,107 \\
\hline Provincial and central & 0.079 & & 6,257 & 0.162887 & 6,644 & 12,900 & 43,800 & 565,040 \\
\hline Private and others & 0.515 & & 40,787 & & & & & \\
\hline Self-treatment $* *$ & & 185,738 & & & & & & \\
\hline Non-treatment $* *$ & & 12,965 & & & & & & \\
\hline Total & & $28 I, 848$ & & & & $28 I, 848$ & & $5,905,492$ \\
\hline
\end{tabular}

*Source: Ministry of Health and General Statistics Office: Results of Vietnam National Household Survey 200 I-02. Hanoi; 2003.

Health care cost per sickness episode is health care cost per visit for outpatients or per admission for inpatients, including hospital fees, drugs, $X$ ray and laboratory tests. The cost does not include indirect (or non-medical) costs, such as costs for travelling, lodging and gifts.

**From table Al.

(3) $=(1) *(2)$

(4) $\mathrm{CHC}=(\mathrm{I}) \mathrm{CHC} /[(\mathrm{I}) \mathrm{CHC}+(\mathrm{I}) \mathrm{DHC}+(\mathrm{I})$ Provincial and central $]$.

(4) $\mathrm{DHC}=(\mathrm{I}) \mathrm{DHC} /[(\mathrm{I}) \mathrm{CHC}+(\mathrm{I}) \mathrm{DHC}+(\mathrm{I})$ Provincial and central $]$.

(4) Provincial and central $=(\mathrm{I})$ Provincial and central/[( $) \mathrm{CHC}+(\mathrm{I}) \mathrm{DHC}+(\mathrm{I})$ Provincial and central $]$.

$(5)=(4) *(3)$ Private and others.

(6) $\mathrm{CHC}=(3) \mathrm{CHC}+(5) \mathrm{CHC}+$ self treatment + non treatment.

(6) $\mathrm{DHC}=(3) \mathrm{DHC}+(5) \mathrm{DHC}$.

(6) Provincial and central $=(3)$ Provincial and central $+(5)$ Provincial and central.

$(8)=(6) *(7)$

All of the respondents who prefer health insurance over out-of-pocket payments in our study will choose to enrol in a health insurance scheme.

The length of stay at provincial and central levels is the same as district level. Because the hypothetical scheme allows for treatment at higher levels if needed, the insured will be compensated by a daily amount equal to the cost per bed day at district level. The cost for treatment at provincial and central levels is the same as the cost for treatment at the district level.

The non-treatment and self-treatment episodes will instead be episodes of out-patient care at commune health centres under the health insurance scheme.

Private health care users will use public health care with the same health care utilisation patterns as those of public health care users.

There are four major reasons why the costs in this system are lower than the current actual health care expenditure in the population. Firstly, none of the administrative costs for the insurance system are included. The costs should therefore be increased by 5-10\%. Secondly, over half of the household health care expenditure in Bavi is spent on private health care. Thirdly, the household health care expenditure includes both direct (e.g. medical costs) and indirect costs (e.g. transportation cost). Finally, costs for care at the provincial and central levels as estimated in our hypothetical system are based on cost per bed day at the district level.

\section{Acknowledgements}

The study was made possible through the financial support provided by SIDA/SAREC through the Health Systems Research Programme in Vietnam.

\section{References}

I. World Health Organization: Health systems: improving performance. World Health Report 2000. Geneva 2000.

2. Ekman B, Liem NT, Duc HA, Axelson $\mathrm{H}$ : Health insurance reform in Vietnam: a review of recent developments and future challenges. Health Policy and Planning 2008, 23:252-263.

3. Xu K, Evans DB, Kawabata K, Zeramdini R, Klavus J, Murray CJL: Household catastrophic health expenditure: a multicountry analysis. The Lancet 2003, 362: III-II7.

4. Prime Minister. Decision number 35/200I/QD-TTg dated March 19, 2002 on Approval strategy on health care for all from 2001 to 2010 . Hanoi, Vietnam . 
5. Wagstaff A: Health Insurance for the Poor: Initial Impacts of Vietnam's Health Care Fund for the Poor. World Bank Policy Research Working Paper 4 I34 2007.

6. Carrin G, James C: Social health insurance: Key factors affecting the transition towards universal coverage. International Social Security Review 2005, 58:45-64.

7. Duong DV, Lee AH, Binns CW: Measuring Preferences for Delivery Services in Rural Vietnam. Birth 2005, 32:194-202.

8. Sepehri A, Sarma S, Simpson W: Does non-profit health insurance reduce financial burden? Evidence from the Vietnam living standards survey panel. Health Economics 2006, 15:603-616.

9. Jowett $M$, Contoyannis $P$, Vinh ND: The impact of public voluntary health insurance on private health expenditures in Vietnam. Social Science and Medicine 2003, 56:333-343.

10. Jowett M, Deolalikar A, Martinsson P: Health insurance and treatment seeking behaviour: evidence from a low-income country. Health Economics 2004, 13:845-857.

11. Wagstaff A: Health Insurance Impacts on Health and Nonmedical Consumption in a Developing Country. World Bank Policy Research Working Paper 35632005.

12. Chang FR, Trivedi PK: Economics of self-medication: theory and evidence. Health Economics 2003, 12:721-739.

13. Sepehri A, Simpson W, Sarma S: The influence of health insurance on hospital admission and length of stay - The case of Vietnam. Social Science and Medicine 2006, 63:1757-1770.

14. Bärnighausen $T$, Liu $Y$, Zhang $X$, Sauerborn R: Willingness to pay for social health insurance among informal sector workers in Wuhan, China: a contingent valuation study. BMC Health Services Research 2007, 7: I I4.

15. Dong H, Kouyate B, Cairns J, Mugisha F, Sauerborn R: Willingnessto-pay for community-based health insurance in Burkino Faso. Health Economics 2003, I 2:849-862.

16. Dong H, Mugisha F, Gbangou A, Kouyate B, Sauerborn R: The feasibility of community-based health insurance in Burkino Faso. Health Policy 2004, 69:45-53.

17. Asenso-Okyere WK, Osei-Akoto I, Anum A, Appiah EN: Willingness to pay for health insurance in a developing economy. A pilot study of the informal sector of Ghana using contingent valuation. Health Policy 1997, 42:223-237.

18. Asgary A, Willis $K$, Taghvaei AA, Rafeian M: Estimating rural households' willingness to pay for health insurance. European Journal of health Economics 2004, 5:209-2I 5.

19. Mathiyazhagan K: Willingness to pay for rural health insurance through community participation in India. International Journal of health planning and management 1998, 13:47-67.

20. Klose $\mathrm{T}$ : The contingent valuation method in health care. Health Policy 1999, 47:97-I23.

21. Drummond MF, Sculpher MJ, Torrance GW, O'Brien BJ, Stoddart GL: Methods for the Economic Evaluation of Health Care Programmes King's Lynn: Oxford University Press; 2005.

22. Dolan P, Olsen JA: Distributing health care. Economic and ethical issues King's Lynn. Oxford University Press; 2002.

23. Long NH, Do TT, Van PH, Anh TT, Chuc NTK: Filabavi DSS, Vietnam. In Population and health in developing countries. Population, Health and Survival at INDEPTH sites Volume 1 . Edited by: Sankoh OA, Kahn K, Mwageri E, Ngom P, Nyarko P. Ottawa: International Development Research Centre; 2002:305-310.

24. Thuan NTB: The burden of household health care expenditure in a rural district in Vietnam. In MPH thesis Nordic School of Public Health, Sweden; 2002.

25. Ha NTH, Berman P, Larsen U: Household utilization and expenditure on private and public health services in Vietnam. Health Policy and Planning 2002, I7:6I-70.

26. Santerre ER, Neun PS: Health Economics: Theory, Insights, and Industry studies Fort Worth: Harcourt Brace College Publishers; 1996.

27. Mladovsky P, Mossialos E: A Conceptual Framework for Community-Based Health Insurance in Low-Income Countries: Social Capital and Economic Development. World Development 2008, 36:590-607.

28. Jowett $\mathrm{M}$ : Theoretical insights into the development of health insurance in low-income countries. In Discussion Paper 188. Centre for Health Economics York University; 2004.

29. Torelli N, Trivellato U: Modeling inaccuracies in job-search duration data. Journal of Econometrics 1993, 59:187-211.
30. Brannas $\mathrm{K}$ : Linear regression with grouped data on the dependent variable. Metrol 1987, 45:63-79.

31. Thanh NX, Lofgren C, Rudholm N, Chuc NTK, Emmelin A, Lindholm L: People's preferences for health care financing options: $A$ choice experiment in rural Vietnam. In Thanh NX, The injury poverty trap in rural Vietnam. PhD thesis Umeå University, Epidemiology and Public health sciences; 2005.

32. Vietnam Social Security: Community-based Health Insurance and School Health Insurance Schemes in Vietnam. Hanoi 2005.

33. Vietnam Social Security: School Health Insurance in Vietnam. Hanoi 2005.

34. Mitchell CR, Carson TR: Using survey to value public goods: The contingent valuation method Washington, D.C.: Resources for the Future; 1989.

35. Cramb RA, Purcell T, Ho TCS: Participatory assessment of rural livelihoods in the Central Highlands of Vietnam. Agricultural Systems 2004, 81 :255-272.

36. Ahmed AU, Hill RV, Smith LC, Wiesmann DM, Frankenberger T: The World's Most Deprived. Characteristics and Causes of Extreme Poverty and Hunger. 2020 Discussion Paper 43, International Food Policy research Institute, Washington 2007.

37. Adams SJ: Vietnam's Health Care System: A Macroeconomic Perspective. Paper prepared for the International Symposium on Health Care Systems in Asia [http://imf.org/external/country/VNM/rr/sp/012105.pdf]. Hitotsubashi University, Tokyo Januari 2I-22 2005

38. Jowett M: Do informal risk sharing networks crowd out public voluntary health insurance? Evidence form Vietnam. Applied Economics 2003, 35: ||53-1|61.

39. Ministry of Health and General Statistics Office: Results of Vietnam National Household Survey 200 I-02. Hanoi 2003.

Publish with Bio Med Central and every scientist can read your work free of charge

"BioMed Central will be the most significant development for disseminating the results of biomedical research in our lifetime. "

Sir Paul Nurse, Cancer Research UK

Your research papers will be:

- available free of charge to the entire biomedical community

- peer reviewed and published immediately upon acceptance

- cited in PubMed and archived on PubMed Central

- yours - you keep the copyright 